\title{
A New Model of China-US Big Power Relations: A Symbolic Sign in Foreign Affairs
}

\author{
Siyuan Huang \\ University of Denver, Denver, USA
}

\begin{abstract}
To cope with the current crisis and tensions full-filled China-US relationship, Chinese President Xi Jinping put forward the concept of building a new model of China-US big power relations, which the US agrees. Yet the new model won a heated discussion. In China this new model was evaluated positively and optimistically, while in the US it was perceived as a strategic challenge or even a threat. In the present article, the author proposes that this new model of China-US big power relations is more like a symbolic sign in foreign affairs rather than a strategic challenge or a threat or an effective and workable mechanism at this moment, and meanwhile analyses this view from diachronic and semiotic perspectives. The analyses reveal that the new model functions as a symbolic sign, signifying to the world that conceptually the two big powers have a good and harmonious relationship.
\end{abstract}

Keywords: a new model of China-US big power relations, a symbolic sign, diachronic perspective, semiotic perspective

\section{Introduction}

In an effort to handle the current crisis and tensions full-filled China-US relationship, Chinese President Xi Jinping put forward the concept of building a new model of China-US big power relations, aiming to free China and the US from the ultimate prophecy of the "Thucydides trap" - an inevitable war between the established power and the rising power. Within this new model, three core characteristics are embodied-no conflict and no confrontation, mutual respect, win-win cooperation. Though this new model is being positively and optimistically reviewed and evaluated by many Chinese scholars, it does cause a flood of discussions among western scholars, especially among American scholars, whose suspicious and negative outlook is dominant in most of the discussions, because this seemingly peaceful rhetoric noticeably emphasizes the importance of "mutual respect" and defines the "mutual respect" of each other's "core national interests" as the bottom line of national survival. However, the core interests include a list of issues that remain dominant and thorny throughout the diplomatic history between China and the US, such as the Taiwan issue, human rights issue, the Tibetan issue, etc. Moreover, China's foreign policy and the official attitude not only become assertive, but also more assertive than it used to be. Under this circumstance, a considerable number of US experts see and perceive this new model as a strategic challenge or even a threat. The present article proposes that this new model of China-US big power relations is more like a symbolic sign in foreign affairs rather than an effective or workable mechanism at this moment, and meanwhile analyses this view from diachronic and semiotic perspectives. 


\section{A Diachronic Perspective to the New Model of China-US Big Power Relations}

China-US relationship is recognized as the most important, complicated, and frustrating bilateral relationship in the 21 st century, though this relationship has never been the easiest one to handle ever since the founding of the People's Republic of China. A fragile relationship is the name used by Harry Harding for his book. Harry Harding is a famous specialist and watcher on China. In his book, Harding provides a detailed description of the evolution of China-US relationship from 1972 to 1989, and he also includes a thorough analysis on the changing contexts for the relationship, including the evolving international environment, changes in American economic and political life, and the dramatic domestic developments in both mainland China and Taiwan. According to Harding (1992), China-US relationship continued to experience the repeated cycle "by which hostility gave way to reconciliation, and euphoria yielded to disenchantment" (p. 358) and is characterized by "an oscillating pattern of progress and stagnation, crisis and consolidation" (p. 5). In other words, this relationship has never been setting in one direction, instead, it is always moving up and down, forward and backward.

The first cycle starts in 1972 when President Nixon paid his historical breakthrough visit to China, representing the normalization between the two countries ever since the founding of the People's Republic of China (PRC). In the statement, Chairman Mao Zedong defined the new China-US relationship as "friendship". After two gapped decades, China and the US for the first time were able to sit at a table to deal with each other and to discuss international affairs. The greatest contributor or the driving factor that pushes China-US relations forward is the common national interest, that is, to form a joint alliance to confront the Soviet Union and limit its expansion and ambition. However, whether this strategic cooperation could be established and maintained largely depends on the progress of Taiwan issue, which is the most dominant controversial issue at that time. In the 1972 Shanghai Communiqué, China and the US reached consensus on hegemony: "Neither side should seek hegemony in the Asia-Pacific region or in any other region of the world and each is opposed to efforts by any other country or group of countries to establish such hegemony" (Joint Communiqué of the United States of America and the People's Republic of China, 1979). Moreover, the US side declared that it recognizes the PRC as the legitimate government and acknowledges that there is only one China and that Taiwan is a part of China. As Hickey argued (2011), the word "acknowledge" was deliberately chosen as it indicates cognizance of but not necessarily agreement with, the Chinese position (p. 233). This clever and deliberate resolution provides great flexibility that allows the US to deal with the cross-strait relationship and to maintain connection with both sides. Most importantly, this Joint Communiqué has set the basic tune for the long-term building process of China-US relations, though both sides still have divergent perspectives in which Chinese leaders insist on the determination of ultimate unification while the US leaders confirm its view of supporting a peaceful settlement. Both Beijing and Washington put the China-US relationship on the top priority, therefore each side has acted with constraint and tried the best to avoid obliging the other side to a test of wills or strength, for example: China has invoked basic principles but has been flexible as to the timing of the implementation; the US has adopted a more pragmatic viewpoint instead of its conventional case to case strategy that could be heavily influenced by domestic American pressure (Kissinger, 2011). It is the congruent interests of the two sides that made the China-US relationship become possible, despite the differences in ideology and values.

The second cycle started from 1978 when the normalization process had been completed, and with the onset of Chinese Economic Reform, economic exchange, educational and cultural communication between 
China and the US start to increase during this period. Though the intersections between both sides continued to expand in various areas including trade, economy, technology, culture and education, the deeply-rooted differences and contradictions in ideology were exposed on many issues, ranging from Taiwan issue to human rights issue. The most serious incident took place in June 1989, that is, the Tiananmen Square Incident, which represents a turning point for China-US relationship. Tiananmen Square Incident aroused great responses and anger in the US and China's human rights issues of both individuals and groups became the dominant issue at that time. Though President senior Bush tried to maintain the normal relationship, American media depicted the PRC as an "arbitrary authoritarian state crushing popular aspirations" and floods of international criticism toward the Chinese government put great pressure on the US leaders to sanction and isolate China to induce it to adopt American values, in other words, to democratize its domestic policies (Kissinger, 2011). The tension between China and the US grow dramatically, pushing China-US relationship to a very dangerous point. Although China side also felt very angry at American interference in her domestic affairs and American intensions to invoke a peaceful revolution, the Chinese government still sought to maintain a relative peaceful international environment to ensure her domestic economic reform and development. Therefore the Chinese government took a low-key stand and followed the foreign policy based on Deng Xiaoping's three principles: Lengjingguancha (carefully assess the situation); Wenzhuzhenjiao (consolidate China's positions); and Chenzhuoyingfu (calmly cope with the challenges) (Jia, 2005, p. 397). Then came a flow of events that were identified as the key turning points, say Clinton Administration's attempt of liking Most Favor Nation (MFN) status with human rights in May 1993; the new Republican-controlled Congress's escalation of tensions toward crisis in 1995-1996; and the 1999 US and NATO's intervention in Yugoslavia (Lampton, 2001).

When entering the 21st century, ironically, the $9 / 11$ terrorist attacks played an important role in turning the progress of China-US relationship. This event changed the priority of US foreign policy and made China seem to be less strategically competitive. In the subsequent years China-US relations kept rising steadily. Until the 2008 global financial crisis, the US economy was heavily struck by this crisis while China's economy not only survived but also made a good performance. China's astounding growth in economics and military power leads to the change to the relative status between China and the US, bringing new turbulences and unstable factors to the relations.

What has been discussed above tells us that owing to the differences between China and the US in such major issues as core national interests, ideology, social values, etc., China-US relationship is fragile, in spite of the fact that China and the US sometimes have to cooperate or to work together to solve the knotty world issues. The history teaches us a lesson: a sign of disturbance or trouble might topple or at least influence China-US relationship. For instance, Tiananmen Square Incident, which has been thought of as internal affairs by the Chinese government, once broke off China-US normal relations. Madsen (1995) even wrote:

This event, I argued, troubled Americans far out of proportion to its direct cost in human life and suffering... The tragedy in China was so upsetting for many Americans because it contradicted widely cherished American understandings of about the meanings of their democratic values - it challenged common interpretations of American Dream. (p. 393)

For Americans, this event can be elevated to the high level of ideology, and in order to demonstrate their justice, they suspended the diplomatic relation between China and the US. There are many other issues such as political, economic, trade, cultural, and diplomatic ones, which China and the US diverge. These issues are the potential land mines, which are easily blown up and can influence China-US relationship. For example, US 
Secretary of State Kerry once said that China-US relationship was the most consequential relationship in the world today and that it would do much to determine the shape of 21 st century. He also frankly expressed that the US would not sit idly by in regards to issues on which there were major differences.

Looking back on history, we have to ask: Is it possible for both China and the US to build a new model of China-US big power relations?

Regarding this new type of big power relations, although both China and the US has reached a consensus on the core significance, actually implementing the specific content remains something that both countries have greatly differing opinions on. Of the three essential characteristics (i.e. no conflict and no confrontation, mutual respect, win-win cooperation), the US agrees that there should be no conflict and no confrontation, believing that conflict should be avoided between emerging nations and established nations. But specifically, the US is focused more on risk management when discussing how to avoid conflict and confrontation, while China hopes to search for the sources of conflict and confrontation. As for the "mutual respect" idea, the US didn't accept this at all, believing that China was using this phrase to try to force the US to make concessions regarding China's core interests. In addition, "win-win cooperation" was not interpreted the same by China as it was by the US. For the three core characteristics, Zhao (2015) wrote:

But Beijing has made it clear that "mutual respect" of each other's "core national interests" is the bottom line. The new model, therefore, is not just another façade on the old rhetoric and peaceful coexistence. Now China and the US can coexist peacefully only if they respect each other's core interests and make their strategic aspirations compatible. (p. 380)

That is to say, to respect each other's core interests is the bottom line, without which the other characteristics cannot exist. Yet, how to define "core interests" is still problematic. And each other's "core interests" might change with the passing of time or with the growth of the aggregate national strength. It is obvious that the three core characteristics at the moment do not have the practical binding force.

Thus, it is clear that a tenuous China-US relationship plus the designation of the bottom line makes it hard for the new model of China-US big power relations to be realized. The new model is more like a symbolic sign in foreign affairs, which signifies to the world that conceptually the two big powers have a good and harmonious relationship.

\section{A Semiotics Reading of the New Model of China-US Big Power Relations}

From semiotics point of view, the construction of the new model of China-US big power relations can be taken as the construction of a sign. As a sign, it must have three elements: (1) Object or sign referent; (2) Representamen or sign expression; (3) Interpretant or meaningful sign interpretation (Peirce, cited in Chandler, 2007). The Object or the sign referent refers to a kind of real, concrete, and substantive relationship, the Representamen or the sign expression a type of imaginary and discourse relationship, and the Interpretant or the meaningful sign interpretation the symbolic meaning (Lanigan, 2015). In other words, the Object or the sign referent refers to the actualized relationship, currently, the seemingly peaceful relationship in the reality. The Representamen or the sign expression refers to those Chinese President Xin Jinping's linguistic expressions such as "no conflict, no confrontation, mutual respect, win-win cooperation", "Cooperation will benefit both sides, fighting will do harm to both sides", "Plant more flowers and less thorns", and so on and so forth. The Interpretant or the meaningful sign interpretation refers to the denotative meaning of those linguistic expressions, that is to say, China and the US work together to construct a mutual respect and cooperative 
relationship.

In communication, each of the three elements of the sign is intertwined with the basic communication perspectives of the constructors of the sign, making the decoding of the new model of China-US big power relations as a sign a problematic issue.

Communication perspectives of the construction of the sign can be divided into three types (direct perspective, meta-perspective, and meta-meta-perspective): “A direct perspective corresponds to Peirce's notion of the Object or sign referent, the meta-perspective to the Representamen or sign expression, and the meta-meta-perspective to the Interpretant or meaningful sign interpretation" (Lanigan, 2015, p. 118).

From a direct perspective, we can see that what Chinese President Xi Jinping talks about is the Object or sign referent of the new model of China-US big power relations as a sign. Here, what Chinese President Xi Jinping focuses on is a kind of concrete, substantive and a tangible relationship in the reality, which US President Obama and all the others cannot refuse. So obviously when Xi's direct perspective meets Obama's direct perspective on the construction of the new model, what they talk about is open, direct, knowing and public, so agreement can be reached. It is a truth that from June 2013 to the present, after a series of events such as "Talks at the Annenberg Estate in California", "The Night Talk at Yingtai in Beijing", "Spring Talk in White House", etc., Chinese President Xi Jinping and American President Obama reached a consensus on building a new model of China-US big power relations. But it is also a fact that this consensus seems just oral. No obvious substantive progress has been made. This might be due to the interrelationship among meta-perspective, meta-meta-perspective and direct perspective.

Meta-perspective refers to "an imaginary version of what is real [Reality]" (Lanigan, 2015, p. 115). It corresponds to the Representamen or sign expression. Simply speaking, when the new model of China-US big power relations is put forward, what $\mathrm{Xi}$ emphasizes is the real relationship in the reality, and what $\mathrm{Xi}$ adopts is the direct perspective. But for Americans, what they face up to is the linguistic expressions or sign expressions at the semiotic level, which is "an imaginary version" or imagining of the reality. So what Americans adopt is meta-perspective. They think some of the information conveyed by Xi Jinping might be overt and covert, and they form their own mental maps based upon the Representamen or sign expression or language of Xi's new model. Their mental maps are different from Xi's. Here, two different perspectives meet each other, which definitely leads to misunderstanding or suspicion or negative evaluation. The fact is that in the US some officials and scholars really hold a skeptical view toward Chinese President Xi's new model of big power relations, seeing this new model as a challenge or a threat to the US, especially when observing that China and the US have drifted farther apart on some topics such as Diaoyu Islands' Issue, South China Sea Issue, etc., and that China even attempted to drive America out of Asian areas over the past several years.

It can be seen that when China's direct perspective encounters American meta-perspective, misunderstanding between the two will arise. So the difference in communication perspective causes the parties concerned to enter into endless arguments about the explicit and implicit meaning and information of the Representamen or sign expression.

Meta-meta-perspective refers to a "symbolic version of what is real", corresponding to the Interpretant or meaningful sign interpretation (Lanigan, 2015, p. 115). In simple words, when Xi proposed this new model to the US, he thought about (meta-meta-perspective) what the US might be thinking (meta-perspective) of what he says (direct-perspective). However, as far as Americans are concerned, they move up the scale from direct to meta-to meta-meta-perspective. In this way, Xi's meta-meta-perspective might encounter American 
meta-perspective or direct perspective, the incongruent might emerge. At this level, Xi thought about what the US might be thinking of his words, so in order to facilitate the construction of the new model of China-US big power relations, in addition to such a clause as "no conflict, no confrontation, mutual respect, win-win cooperation", Chinese President Xi Jinping makes full use of positive words to address the US officials. For instance, in November 2014, when Chinese President Xi Jinping met US President Obama in Zhong Nan Hai, he urged Obama to further build China-US big power relations by uttering the following utterances:

The history of 35-year-diplamatic relationship between China-US has proven that a good China-US relationship is in the fundamental interests of both peoples, Asian-Pacific regions and the world. This is the strategic consensus that both leaders insist on. Now the strategic goals of China-US new big power relations are clear. We should not let it be and should not be content with the early achievement. We should walk forward. We must start from the strategic and long-standing perspective, with the spirit of "little drops of water making an ocean, and many sands piled up making a mountain", further pushing the construction of China-US big power relations forward. (Yingtai Talk between Xi Jinping and Obama in Zhong Nan Hai, 2014)

$\mathrm{Xi}$ attempted to use these positive expressions to strengthen China-US benign big power relations, telling the US China's wishes, efforts and thinking. Nevertheless, for the US, they may not think about what Xi thought about what the US might be thinking of his words, they may image about China's verbal (including words, sentences, etc.) and nonverbal expressions (i.e. establishing An Air Defense Identification Zone, de-Americanization, etc.), and when they find the incongruent between China's verbal and nonverbal expressions, they demonstrate their suspicion, distrust, dissatisfaction, or even threat by verbal or nonverbal means. The recent event that the US warships entered the South China Sea is such a typical example.

This analysis further proves that differences in semiotic communication perspectives between China and the US can make China and the US diverge on many topics. If both sides communicate at the same perspective level, the differences might be minimized. Yet this is completely impossible. Under this circumstance, it can be predicted that both China and the US cannot reach a substantial agreement on the new model of China-US big power relations. The new model is more than a sign. It is a symbolic sign.

To sum up, the above analysis reveals that the interpretation of this new model of China-US big power relations cannot be unanimously positive by China and the US owing to differences in semiotic communication perspectives. Underlying the differences are such invisible factors as core national interests, ideology, social system, social value, strategic plans, economic and trade benefits, culture, thinking patterns, deep-rooted suspicion, etc., which China and the US diverge greatly. So obviously, both China and the US cannot have any substantial advance on the new model of China-US big power relations. "Both sides remain friendly in appearance but estranged at heart". Thus, it is impossible for this new model to pose a challenge or a threat to the US. And this new model cannot really make China and the US cooperate in a comprehensive way. This model just functions as a symbolic sign. As a sign, the model of China-US big power relations has its Object or sign referent, the Representamen or sign expression, the Interpretant or meaningful sign interpretation. But this sign is a symbol. It shows the world that the two big powers in the current world are getting along well with each other.

\section{Conclusions}

In early 2012, when Xi Jinping, who was then Vice President of China, visited the US, he proposed the idea of a new model of big power relations between China and the US. In June 2013, Xi Jinping as the 
President of China visited the US and had an unprecedented Sunnylands Center and Gardens meeting with US President Obama. There both leaders reached an initial consensus regarding China and the US building a new type of big power relations. At the time, Xi Jinping brought up three core issues: "What sort of Sino-US relations are needed?"; "What sort of cooperation should China and the US have for mutual benefits?"; and "How should China and the US partner promote world peace and development?" The answer that Xi gave was that China and the US should drive forward a new model of big power relations. The new model of China-US big power relations defines the term "big power" as the world's most powerful developed country and the world's largest developing country, and lists three essential characteristics that this relationship should have as "no conflict and no confrontation, mutual respect, and win-win cooperation". This model, like the ripples spreading when a stone is thrown into the water, sparked great interests from a large number of politicians and scholars, but their opinions are greatly divided. Some are too optimistic, and some too pessimistic.

In the present article, the author proposes that this new model of China-US big power relations is at most a symbolic sign, and simultaneously attempts to verify this argument from two aspects: first by using the historical view to examine the fragile China-US relationship and to explain why this new model is just a symbolic sign; second by employing the semiotic approach to analyze why the new model is at best a symbolic sign. The study discloses that the new model of China-US big powers relations is not a cooperative paradigm, a challenge, or even a threat, instead it is more like a symbolic sign, which signifies that the two big powers can co-exist peacefully or "a mountain can accommodate two tigers" as the Chinese idiom describes.

\section{References}

Chandler, D. (2007). Semiotics: The basics. New York, NY: Routledge.

Harding, H. (1992). A fragile relationship: The United States and China since 1972. Washington, DC: Brookings Institution Press.

Hickey, D. (2011). Rapprochement between Taiwan and the Chinese mainland: Implications for American foreign policy. Journal of Contemporary China, 20(69), 231-247.

Jia, Q. G. (2005). Learning to live with the hegemon: Evolution of China's policy toward the US since the end of the Cold War. Journal of Contemporary China, 14(44), 395-407.

Joint Communiqué of the United States of America and the People's Republic of China. (January 1, 1979). Retrieved from http://www.taiwandocuments.org/communique02.htm

Kissinger, H. (2011). On China. New York, NY: Penguin Press.

Lampton, D. M. (2001). Same bed, different dreams: Managing US-China relations, 1989-2000. Berkeley, CA: University of California Press.

Lanigan, R. (2015). Semiotic paradigms of self and person: The perspectives model of communicology as the logic foundation of human science. Language and Semiotic Studies, 1(1), 106-129.

Madsen, R. (1995). China and the American Dream: A moral inquiry. Berkeley, CA: University of California Press.

Yingtai Talk between Xi Jinping and Obama in Zhong Nan Hai (习近平与奥巴马中南海瀛台谈话内容公布). (2014, November 14). Retrieved from http://news.ifeng.com/a/20141114/42473210_0.shtml

Zhao, S. S. (2015). A new model of big power relations? China-US strategic rivalry and balance of power in the Asia-Pacific. Journal of Contemporary China, 24(93), 377-397. 